\title{
The health effects of ultrafine particles
}

\author{
Dean E. Schraufnagel ${ }^{1}$
}

\begin{abstract}
Ultrafine particles $\left(\mathrm{PM}_{0.1}\right)$, which are present in the air in large numbers, pose a health risk. They generally enter the body through the lungs but translocate to essentially all organs. Compared to fine particles $\left(\mathrm{PM}_{2.5}\right)$, they cause more pulmonary inflammation and are retained longer in the lung. Their toxicity is increased with smaller size, larger surface area, adsorbed surface material, and the physical characteristics of the particles. Exposure to $\mathrm{PM}_{0.1}$ induces cough and worsens asthma. Metal fume fever is a systemic disease of lung inflammation most likely caused by $\mathrm{PM}_{0.1}$. The disease is manifested by systemic symptoms hours after exposure to metal fumes, usually through welding. $\mathrm{PM}_{0.1}$ cause systemic inflammation, endothelial dysfunction, and coagulation changes that predispose individuals to ischemic cardiovascular disease and hypertension. $\mathrm{PM}_{0.1}$ are also linked to diabetes and cancer. $\mathrm{PM}_{0.1}$ can travel up the olfactory nerves to the brain and cause cerebral and autonomic dysfunction. Moreover, in utero exposure increases the risk of low birthweight. Although exposure is commonly attributed to traffic exhaust, monitored students in Ghana showed the highest exposures in a home near a trash burning site, in a bedroom with burning coils employed to abate mosquitos, in a home of an adult smoker, and in home kitchens during domestic cooking. The high point-source production and rapid redistribution make incidental exposure common, confound general population studies and are compounded by the lack of global standards and national reporting. The potential for $\mathrm{PM}_{0.1}$ to cause harm to health is great, but their precise role in many illnesses is still unknown and calls for more research.
\end{abstract}

\section{Introduction}

Air pollution can harm nearly every organ in the body ${ }^{1,2}$, and particulate matter (PM) is the main offender. PM has been classified by particle size, which is an important factor in its health effects. $\mathrm{PM}_{10}$ (particles $\leq 10 \mu \mathrm{m}$ in diameter), $\mathrm{PM}_{2.5}$ (particles $\leq 2.5 \mu \mathrm{m}$ in diameter), also called fine particles, and $\mathrm{PM}_{0.1}$ (particles $\leq 0.1 \mu \mathrm{m}$ in diameter), also called ultrafine particles (this term is used interchangeably with $\mathrm{PM}_{0.1}$ in this document), have different health effects that, in part, result from how these particles navigate the small bronchioles and lung defenses. $\mathrm{PM}_{0.1}$ are also called nanoparticles because of their size, although many authors restrict the word "nanoparticles" to the 100-nm or smaller particles produced by controlled engineering processes ${ }^{3}$.

Correspondence: Dean E Schraufnagel (schrauf@uicedu)

'Division of Pulmonary, Critical Care, Sleep, and Allergy, Department of Medicine, University of Illinois at Chicago, M/C719, 840 S. Wood St., Chicago, IL 60612, USA
Ultrafine particles are dispersed atmospherically in many settings ${ }^{4}$. Examples are found in nature, from forest fires, ocean splashes, and viruses; combustion processes, from vehicular and power plant emissions and tobacco smoking; and synthetic sources, from toner pigment and many engineered products used for microtechnology. These particles may be formed by the coalescence of ions and gaseous molecules produced by combustion, often as acidic and basic ions or other charged species that combine to form more stable molecules or salts. This process, which usually depends on aqueous oxidation, may explain the sulfate levels of London fog of $1952^{5}$ and the effects of humidity on the symptoms of patients with respiratory disease. Coalescing $\mathrm{PM}_{0.1}$ are a major source of $\mathrm{PM}_{2.5}$.

The harmful effects of the different PM categories overlap because the corresponding sizes overlap; $\mathrm{PM}_{10}$, which include all smaller particles, will have similar effects to those of smaller PMs, although the effects can be distinguished by taking mass into account. $\mathrm{PM}_{10}$ and $\mathrm{PM}_{2.5}$ 
are measured by their mass, while $\mathrm{PM}_{0.1}$ are measured by particle number.

\section{Numbers of particles}

A typical concentration of $\mathrm{PM}_{0.1}$ in ambient air in rural areas is 2610 particles $/ \mathrm{cm}^{3}$, whereas a roadside concentration may be $48,180 / \mathrm{cm}^{3}$, with a mean global concentration of $10,760 / \mathrm{cm}^{3}$. The large numbers of $\mathrm{PM}_{0.1}$ quickly diminish by amalgamation into larger particles and atmospheric dispersion, resulting in local concentrations or "hotspots" near traffic or sites of industrial production. It is paradoxical that $\mathrm{PM}_{0.1}$ particle numbers decrease quickly by coalescence, yet remain airborne for extended periods and can travel to other continents. Peak concentrations of traffic emissions occur near curbsides, and these levels are often more than ten-fold higher than the background. The concentrations regress to background by $\sim 500 \mathrm{~m}$ from the source ${ }^{6}$. High concentrations are associated with many different conditions, such as high humidity, low air movement, increased number of diesel vehicles, seasons, and traffic acceleration after stopping $^{3}$. Improvements in fuel and engine technology and the use of catalytic converters have reduced the PM mass and carbon monoxide (CO) from automotive exhaust but have increased the number and toxicity of $\mathrm{PM}_{0.1}{ }^{7,8}$.

Occupational exposures, especially those associated with combustion or high temperature, such as welding or blast furnace operation, may be great. The highest concentrations of $\mathrm{PM}_{0.1}$ are found in welding facilities, machine shops, basic metal industries, traffic-related occupations, and restaurants, with concentrations of $0.7-4.7 \times 10^{6}, 60-450$ times higher than the background levels ${ }^{3}$.

As particle sizes decrease, the numbers increase, especially when such particles approach the size of $\mathrm{PM}_{0.1}$. Coarse particles $\left(\mathrm{PM}_{10-2.5}\right)$ accounted for $<0.1 \%$ of the total particle numbers in a study from Shenyang, China ${ }^{9}$. An airborne concentration of $10 \mu \mathrm{g} / \mathrm{m}^{3}$ would require $2.4 \times 10^{6} 20$-nm particles, but only one $2.5-\mu \mathrm{m}$ particle/ $\mathrm{cm}^{3,10}$. With the particle number and total surface area as important parameters, the mass measurements used for $\mathrm{PM}_{10}$ and $\mathrm{PM}_{2.5}$ are not useful for $\mathrm{PM}_{0.1}$. Particle numbers are so much greater for $\mathrm{PM}_{0.1}$ that this measurement is used to estimate $\mathrm{PM}_{0.1}$ concentrations.

The variation in $\mathrm{PM}_{0.1}$ number with season and location was highlighted by a European study that found that Augsburg, Helsinki, and Stockholm had mean annual concentrations of particles between 10,000 and $11,000 \mathrm{~cm}^{-3}$, but winter concentrations were almost twice that much (between 10,000 and $20,000 \mathrm{~cm}^{-3}$ ), and summer concentrations were approximately half that much (between 5000 and 6000 particles $\mathrm{cm}^{-3}$. Rome and Barcelona, which have greater air pollution, had average annual concentrations of $\mathrm{PM}_{0.1}$ of more than 43,000 and $39,000 \mathrm{~cm}^{-3}$, respectively, but winter concentrations of $100,000 \mathrm{~cm}^{-3}$. This study also reported diurnal and weekday variations, with daily peak levels between $7 \mathrm{a} . \mathrm{m}$. and 10 a.m. in most places. Sunday had $\sim 2 / 3$ of the weekday concentrations ${ }^{11}$. The variation and fluctuating nature of the exposure makes monitoring, gauging their health effects, and setting standards difficult.

The hourly average exposure over a year of $\mathrm{PM}_{0.1}$ differs from that of $\mathrm{PM}_{2.5}$ in that the distribution of $\mathrm{PM}_{0.1}$ is more skewed and widely spread owing to their more rapid reduction and dispersal. The greater diurnal trend for $\mathrm{PM}_{0.1}$ results from the variation in vehicular emissions. $\mathrm{PM}_{0.1}$ and $\mathrm{PM}_{2.5}$ are not well correlated; the ratio of the particle number-to-mass ratio was found to be highest at roadside sites (indicating a prominence of $\mathrm{PM}_{0.1}$ ) and lowest in polluted cities (indicating a prominence of $\mathrm{PM}_{2.5}$ ). Regulating $\mathrm{PM}_{2.5}$ may not significantly reduce $\mathrm{PM}_{0.1}{ }^{12}$.

\section{Absorption and retention of $\mathbf{P M}_{\mathbf{0 . 1}}$}

Most inhaled particles of $10 \mu \mathrm{m}$ or larger in aerodynamic diameter impact the nasopharyngeal membranes. Inhaled particles of 5-10 $\mu \mathrm{m}$ usually land on the airways and are normally removed by alveolar macrophages and lung lymphatics ${ }^{1}$. Particles in the range of $1-2.5 \mu \mathrm{m}$ usually make their way to the terminal bronchiole, the site of greatest accumulation and tissue destruction, as commonly seen in centrilobular emphysema. Particles $<1 \mu \mathrm{m}$ stay airborne longer and easily gain access to alveoli. Although most PM sizes can be engulfed by cells, $\mathrm{PM}_{0.1}$ translocate transcellularly across alveolar epithelial cells by diffusion through the lipid bilayer of the cell walls ${ }^{13}$. It is not just phagocytic cells that pick up material. All cells absorb cellular fragments of senescent, damaged, or normal cells and exchange and recycle molecular material ${ }^{14}$. The cellular fragments (sometimes termed extracellular vesicles) could easily harbor $\mathrm{PM}_{0.1}$.

In an in vitro model, investigators showed that positively charged $\mathrm{PM}_{0.1}$ penetrated cells 20-40 times more than negatively charged particles ${ }^{13}$. Although this result may be specific to the cells tested, it points out the importance of surface charge. An important property of $\mathrm{PM}_{0.1}$ is the large surface-area to mass ratio that allows the particles to carry large amounts of adsorbed materials per unit mass. The large variety of compounds that attach to these particles is likely to be a major cause of their toxicity, but the great variation of adsorbed material makes it more difficult to link $\mathrm{PM}_{0.1}$ to specific conditions. Other properties, such as aspect ratio, charge, surface reactivity, solubility, hydrophobicity or polarity, agglomeration state, and the ability to interact with biologic tissue and generate reactive oxygen species, are important determinants of toxicity. 
$\mathrm{PM}_{0.1}$ that enter alveoli can be retained in surfactant ${ }^{15}$, thus sidestepping the mucociliary escalator clearance mechanisms. The retention half-life of titanium dioxide $\left(\mathrm{TiO}_{2}\right)$ particles of the identical crystalline structure, deposition burden, and conditions in animal lungs was reported to be 170 days for 250 -nm particles and 500 days for 20-nm particles ${ }^{16}$. The finer particles caused stronger and more persistent inflammation, with more type II cell proliferation and macrophage impairment and early interstitial fibrotic foci. The small particles also moved into the lung interstitium and periphery more than the larger ones ${ }^{16} . \mathrm{TiO}_{2}$, which is considered a safe additive to foods, toothpaste, lotions, and many other household products, appears to have many major toxic effects when its particles are in the $\mathrm{PM}_{0.1}$ range ${ }^{17}$.

\section{Health effects}

The first interaction site for $\mathrm{PM}_{0.1}$ is the lung. The surface area of the lung has been estimated to be more than $100 \mathrm{~m}^{218}$, but this is commonly estimated by measuring linear intercepts with a $1-\mu \mathrm{m}$ probe by light microscopy. The estimate of the surface area becomes larger as the sampling probe becomes smaller, accounting for the additional surface area of an irregular surface. The surface area of the lung to a nanoprobe of $\mathrm{PM}_{0.1}$ would be orders of magnitude greater than the light microscopy estimates, something Weibel referred to as the "Coast of Wales" effect ${ }^{19}$.

$\mathrm{PM}_{0.1}$, along with their toxic baggage, easily reach the large surface of the lung. They subsequently gain access to other organs through the lung vasculature, either through mobile cells or freely in the vasculature and lymph to directly harm distal organs. Another mechanism by which $\mathrm{PM}_{0.1}$ cause harm is lung inflammation and the subsequent spread of inflammatory mediators to distal organs. This is considered the main cause of systemic toxicity for larger PM, which are less able to directly access other organs. In addition to having better access, $\mathrm{PM}_{0.1}$ have more toxicity in cellular and animal models ${ }^{20}$. For example, low-solubility and low-toxicity $\mathrm{PM}_{0.1}$ cause more inflammation in rat lungs than $\mathrm{PM}_{2.5}$ of the same material $^{21}$.

Other explanations for the increased toxicity of $\mathrm{PM}_{0.1}$ include the fact that many smaller particles may stress alveolar macrophages more than fewer large ones. This could also explain why clearance is dependent on particle size. Inflammation in response to noxious material on the surface of particles and interactions with the cell surfaces of host tissues would also be greater with ultrafine particles $^{22}$. Another important point when considering human population studies is that $\mathrm{PM}_{2.5}$ have more immediate effects, while $\mathrm{PM}_{0.1}$ have more delayed effects and a greater influence on mortality ${ }^{23}$. Most epidemiologic studies of acute exposure to $\mathrm{PM}_{0.1}$ take into account a lag time between exposure and symptoms of 1-5 days to account for the delayed effect.

Compared to data on $\mathrm{PM}_{2.5}$ and $\mathrm{PM}_{10}$, there is a paucity of information on the long-term health effects of $\mathrm{PM}_{0.1}$. A major reason for this is the lack of international standards and national reporting. Although $\mathrm{PM}_{0.1}$ can be readily measured in the atmosphere, the measuring instruments are not standardized, which means methods and protocols vary $^{24}$. Developing standards is difficult for populations because of the variable nature of personal exposures and the silent nature of the effects of air pollution, particularly $\mathrm{PM}_{0.1}$. Neither clinicians nor the public generally consider air pollution as a cause of a specific illness. Many exposures, such as to office printers, would go unnoticed by most workers.

The study of $\mathrm{PM}_{0.1}$ has been aided by engineered nanoparticles. Ultrafine particles can be manufactured with a high degree of accuracy with regard to their size, shape, and composition. The biological effects of these factors can then be studied more precisely. Engineered nanoparticles can be applied to cells and tissues and given as a challenge to animals and human volunteers. For example, high doses of fibrous and tubular nanostructures can result in fibrotic lung reactions and an increased risk of carcinogenesis ${ }^{25}$. Single-walled nanotubes can persist deep in the lung and induce inflammatory and fibrotic reactions ${ }^{26}$. Many other studies have shown various intracellular effects depending on the species studied and the nature of the nanoparticle ${ }^{25}$.

\section{Diseases}

A review of all diseases associated with $\mathrm{PM}_{0.1}$ is beyond the scope of this paper, but the following discussion highlights major associations. Air pollution and its effects on different organ systems have recently been reviewed ${ }^{1,2}$.

\section{Respiratory}

The respiratory system is usually the first line of entry into the body for air pollution, but ingested $\mathrm{PM}_{0.1}$ pass through the gastrointestinal tract and can stimulate immune responses in animals and human colonic biopsies. In a Western diet, more than $10^{12}$ ultrafine particles are ingested daily by a single person ${ }^{27}$. Intact skin is generally considered protective. Short-term exposure to $\mathrm{PM}_{0.1}$ with a high content of polycyclic aromatic hydrocarbons increases 8-hydroxyl-2-deoxyguanosine, a byproduct of DNA oxidative damage, in children with eczema but not in those without eczema ${ }^{28}$, although particles of zinc and $\mathrm{TiO}$ used in topical skin care have been shown to penetrate intact skin, especially in watery or oily vehicles ${ }^{29}$.

\section{Metal fume fever and polymer fume fever}

Metal fume fever is an example of a disease most likely caused by $\mathrm{PM}_{0.1}$. $\mathrm{PM}_{0.1}$ are produced by welding. Inhaling 
the small particles generates a great amount of reactive oxygen species, leading to inflammation ${ }^{30}$. Metal fume fever usually presents with malaise, fever, chills, arthralgias, and myalgias $4-8 \mathrm{~h}$ after exposure to metal fumes, usually through welding. Chest radiographs are inconsistent, and the syndrome generally abates without treatment. Although zinc oxide $(\mathrm{ZnO})$ has been incriminated, other metals, namely, copper, magnesium, and cadmium, have also been identified. A similar syndrome, polymer fume fever, has been associated with inhalation of fluorinated polymer products, such as polytetrafluoroethylene (Teflon $\left.{ }^{\Phi}\right)$. Heated polytetrafluoroethylene contains ultrafine particles (median diameter $26 \mathrm{~nm}$ ) that are toxic to rats, causing hemorrhagic pulmonary inflammation and death with highdose exposure and decreased function with low-dose exposure $^{31}$. Short-term, high-level exposure to $\mathrm{PM}_{0.1}$, such as through diesel exhaust, also causes lung inflammation ${ }^{32}$.

The respiratory mucociliary apparatus is a major tool to clear inhaled particles. Although ultrafine particles can be trapped in the mucous layer, its role in clearance is far less than that for PM of greater density, which impacts the airway. Many lung conditions impair mucociliary function. Ciliary dysfunction is common in smokers and those with respiratory tract infections and may account for the greater vulnerability of these individuals to air pollution. Bronchospasm and cough, which are part of asthma, are common reactions to inhaled irritants, which may account for the increased sensitivity in persons with asthma.

Particulate air pollution is a well-known cause of exacerbations and mortality in persons with chronic obstructive pulmonary disease (COPD), but the role of $\mathrm{PM}_{0.1}$ is unclear. A study from Scotland did not find $\mathrm{PM}_{0.1}$ to be more harmful than $\mathrm{PM}_{10}{ }^{33}$, but other studies have reported that indoor biological $\mathrm{PM}_{0.1}$ in the form of bacterial extracellular vesicles do cause inflammation and emphysema $^{34}$.

Ambient exposure to $\mathrm{PM}_{0.1}$ is associated with cough, reduced peak expiratory flow ${ }^{35}$, and the increased use of medicines $^{36}$ and hospital admissions for persons with asthma ${ }^{37}$. Clinical visits for respiratory illness are associated with increased levels of $\mathrm{PM}_{0.1}{ }^{38}$. Although most studies have found an increase in asthma symptoms, a study of more than a million adult residents of Toronto did not find evidence for an association between longterm exposure to $\mathrm{PM}_{0.1}$ and respiratory disease after adjusting for $\mathrm{PM}_{2.5}, \mathrm{NO}_{2}$, and other covariates ${ }^{39}$. An Australian controlled study also did not find particle number to be independently associated with respiratory symptoms, asthma diagnosis, or lung function, although $\mathrm{PM}_{0.1}$ was associated with an increase in inflammatory markers in atopic participants ${ }^{40}$.

\section{Cardiovascular}

Many studies have shown that PM causes systemic inflammation and coagulation changes predisposing to ischemic cardiovascular disease, as measured by elevated C-reactive protein (CRP), circulating polymorphonuclear leukocytes, platelets, fibrinogen, plasma viscosity and other markers. PM promotes endothelial dysfunction, vascular inflammation, and atherosclerosis ${ }^{1}$. Past studies have attributed this effect mainly to $\mathrm{PM}_{2.5}$, but a growing body of literature shows that $\mathrm{PM}_{0.1}$ have a major role in essentially all of these factors ${ }^{41-43}$. In fact, most studies show a far greater effect for $\mathrm{PM}_{0.1} \cdot \mathrm{PM}_{0.1}$ also cause increased heart rate variability, loss of sympathovagal balance, and altered inflammatory and hemostatic function in exposed humans ${ }^{44}$.

Even brief exposures to $\mathrm{PM}_{0.1}$ can cause cardiac effects. In middle-aged individuals with metabolic syndrome, exposure to $\mathrm{PM}_{0.1}$ for $2 \mathrm{~h}$ caused electrocardiographic changes, a decrease in blood plasminogen and thrombomodulin and an increase in CRP and serum amyloid $\mathrm{A}^{45}$.

Many studies have shown an association between chronic exposure to $\mathrm{PM}_{0.1}$ and heart disease. A prospective study of 33,831 Dutch residents found that longterm exposure to $\mathrm{PM}_{0.1}$ (measured by land use regression) was associated with an increased risk for cardiovascular disease, myocardial infarction, and heart failure ${ }^{46}$. In adults living in Toronto from 1996 to 2012, an increase in $\mathrm{PM}_{0.1}$ exposure was associated with an increased incidence of heart failure and acute myocardial infarction. Adjustment for $\mathrm{PM}_{2.5}$ and $\mathrm{NO}_{2}$ did not change these associations, although $\mathrm{NO}_{2}$ was also independently associated with increased heart failure incidence ${ }^{47}$. Mobile neighborhood monitoring found the annual average particle number exposures to be associated with stroke, ischemic heart disease, and hypertension ${ }^{48}$. Other studies have also found increased ischemic and thrombotic stroke with $\mathrm{PM}_{0.1}$ exposure ${ }^{49}$ and increased blood pressure and worse microvascular function with $\mathrm{PM}_{0.1}$ but not with $\mathrm{PM}_{2.5}$ and $\mathrm{PM}_{10}{ }^{43,50}$.

Particle size has been correlated with total and cardiovascular mortality, with the correlation becoming stronger as the particle size decreases. $\mathrm{PM}<0.50 \mu \mathrm{m}$ had the highest correlation ${ }^{9,51}$. No association was found for mass concentrations $\left(\mathrm{PM}_{2.5} \text { and larger }\right)^{51}$.

Particle numbers are associated with cardiovascular disease-related emergency department visits, with a lag of 4-10 days; $10-50 \mathrm{~nm}$ particles mainly account for this finding. $\mathrm{PM}_{0.1}$ were reported to account for more than $7 \%$ of emergency department visits ${ }^{52}$. The strongest correlate of immediate effect (within 2 days) was found with 30-100-nm particles, despite a small mass concentration. The immediate effect related to mass concentration was with the $1-5 \mu \mathrm{m}$ particles, which had a similar delayed effect to the $\mathrm{PM}_{0.1}$ number ${ }^{52}$. 
A study of more than 100,000 women in California found that mortality from ischemic heart disease was more strongly associated with $\mathrm{PM}_{0.1}$ than with $\mathrm{PM}_{2.5}{ }^{53}$. Repeated biweekly submaximal exercise tests on adult subjects with stable coronary heart disease showed that $\mathrm{PM}_{0.1}$ were associated with electrocardiographic STsegment depression of $>0.1 \mathrm{mV}$. The researchers found that the $\mathrm{PM}_{0.1}$ effect was independent of $\mathrm{PM}_{2.5} \cdot \mathrm{NO}_{2}$ and $\mathrm{CO}$ were also associated with a risk for ST-segment depression, but coarse particles $\left(\mathrm{PM}_{10-2.5}\right)$ were not ${ }^{54}$.

However, a study from Denmark of 6515 airport workers who were exposed to long-term $\mathrm{PM}_{0.1}$ found no correlation with ischemic heart disease or cerebrovascular disease compared to the corresponding measures in a similar group of unskilled workers ${ }^{55}$.

\section{Central nervous system}

Many articles have been published on the brain or neural effects of PM, and there is a great deal of animal work on the mechanisms by which $\mathrm{PM}_{0.1}$ affect the brain and its development. Translocated $\mathrm{PM}_{0.1}$ can be found in the brain within $4-24 \mathrm{~h}$ after inhalation. Nasal $\mathrm{PM}_{0.1}$ can travel up the olfactory nerves to the brain. Animals exposed to aerosols of $\mathrm{PM}_{0.1}$ have the greatest brain uptake in the olfactory bulb, even 7 days after exposure. In an animal inhalation study, up to $20 \%$ of the $\mathrm{PM}_{0.1}$ deposited on the olfactory mucosa moved to the olfactory bulb ${ }^{56}$. This pathway, which could circumvent the blood brain barrier, may be even more direct in humans ${ }^{57} \cdot \mathrm{PM}_{0.1}$ not only translocate and directly damage neural tissue but also affect autonomic function. Exposure to $\mathrm{PM}_{0.1}$ increases sympathetic nervous system activity by decreasing norepinephrine clearance, a feature that is increased with concurrent ozone $\left(\mathrm{O}_{3}\right)$ exposure ${ }^{58}$.

Considerable animal research has been carried out on the effect of $\mathrm{PM}_{0.1}$ on brain development. Postnatally, $\mathrm{PM}_{0.1}$-exposed animals show short-term memory impairment, cortical and hippocampal changes, which raise the potential for excitotoxicity, and long-term glial activation, which is associated with a wide range of behavioral and other neurologic effects ${ }^{59}$. Pregnant mice administered carbon black nanoparticles intranasally gave birth to offspring with a dose-dependent, long-term activation of astrocytes. Many mRNA level changes associated with angiogenesis, cell migration, proliferation, chemotaxis, and growth factors caused the authors to speculate that this exposure could have wide-ranging implications for health in later life ${ }^{60}$. Other animal studies have shown that $\mathrm{PM}_{0.1}$ affects emotional behavior, learning capability, neurotransmission, spontaneous motor activity, and avoidance of performance ${ }^{61}$.

In humans, regular exercise has been shown to improve brain cognition and memory. One mechanism for this effect may be by upregulating brain-derived neurotrophic factor (BDNF). BDNF was measured in subjects before and after cycling for $\sim 20$ min near major traffic and, on another occasion, in a room with air filtered to remove $\mathrm{PM}_{0.1}$ as well larger PM. The average $\mathrm{PM}_{0.1}$ was 28,180 particles $/ \mathrm{cm}^{3}$ near the road and 496 particles $/ \mathrm{cm}^{3}$ in the air-filtered room. Serum BDNF concentration rose after cycling in the air-filtered room but not after cycling near the major traffic route ${ }^{62}$.

\section{Children}

Children are more vulnerable to the health effects of air pollution, and these effects may begin with in utero exposure and have lifelong consequences ${ }^{1}$. Exposure of pregnant women to $\mathrm{PM}_{0.1}$ increases the risk of low birthweight, especially in those living within $50 \mathrm{~m}$ of heavy traffic ${ }^{63}$.

A study from Ghana monitored the personal exposure of 61 junior high school students $24 \mathrm{~h}$ per day for 10 weeks. The exposures varied greatly depending on place of residence and the type of activities in which the students were engaged. The highest exposures were in a home near a trash burning site, in a bedroom with burning coils employed to abate mosquitos, in a home with an adult smoker, and in home kitchens during domestic cooking ${ }^{64}$. A similar study conducted in the Pearl River delta in China that monitored school children (aged 9-13) for 2 weeks found that the highest exposures were indoors, associated with smoking adults and the use of mosquito repellent incense ${ }^{65}$. These studies show that the sources of $\mathrm{PM}_{0.1}$ are not always predictable and are not only related to vehicular traffic. Microenvironments and chance exposure have important implications for epidemiologic studies.

A major source of $\mathrm{PM}_{0.1}$ for children living in rural areas can be exhaust from school buses, especially if they are older diesel-powered vehicles. Filtration of the inside air in school buses has been shown to significantly decrease the number of in-cabin ultrafine particles ${ }^{66}$. Exposure also occurs when children are in the playground and standing outdoors while waiting to enter the bus. Idling engines produce more $\mathrm{PM}_{0.1}$ than driving does ${ }^{67}$. These exposures can be reduced by anti-idling policies.

Electronic cigarettes are now commonly used by children and are a source of inhaled $\mathrm{PM}_{0.1}{ }^{68}$. Electronic cigarettes use heated vehicles (usually propylene glycol and glycerol) to deliver microaerosols to the lungs. They also deliver $\mathrm{PM}_{0.1}$ to the brain along with nicotine. Highresistance coils in electronic cigarettes and increased glycerol generate larger particles, and higher coil temperatures generate smaller particles. Particles produced by the electronic cigarettes are deposited in alveoli ${ }^{69}$.

\section{Diabetes}

Air pollution affects many metabolic functions and has been associated with diabetes and other metabolic 
illnesses. Exposure to $\mathrm{PM}_{0.1}$ and $\mathrm{NO}_{2}$ from traffic-related sources increases the risk for hypertension and diabetes ${ }^{70}$. A single 2-h inhalation of elemental carbon $\mathrm{PM}_{0.1}$ had an effect on heart variability in diabetic subjects that lasted for hours ${ }^{71} \cdot \mathrm{PM}_{0.1}$ cause autonomic dysfunction ${ }^{72}$ and affect glucose tolerance in patients with diabetes ${ }^{73}$.

\section{Cancer}

Many studies in animals and human cells have shown that PM is mutagenic and tumorigenic ${ }^{61}$, and it appears that the finer the particle size, the greater the mutagenic potential ${ }^{74} \cdot \mathrm{PM}_{0.1}$ from the atmosphere and roadside contain many mutagenic particles ${ }^{75} \cdot \mathrm{PM}_{0.1}$ have been shown to produce tumors in rats. The strongest tumorigenic factor was the total surface area of the retained particles, although the dose, particle type, and duration of exposure were also important. Smaller aggregated ultrafine $\mathrm{TiO}_{2}$-induced lung tumors in rats much more than larger sized $\mathrm{TiO}_{2}{ }^{22}$. The carcinogenic properties of nanoparticles are related to their aspect ratio and rigidness ${ }^{76}$.

\section{Conclusions}

The potential for $\mathrm{PM}_{0.1}$ to cause harm to health is great, but their precise role in many illnesses is still unknown. Their high point-source production and rapid redistribution make incidental exposure common for the general population and confound general population studies. This has, no doubt, contributed to the lack of global standards and national reporting. The absence of standards and reporting may account for the dearth of standardized measurements, instruments, and protocols. Air pollution is a silent epidemic ${ }^{77}$, and $\mathrm{PM}_{0.1}$ may be the quietest of the pollutants. $\mathrm{PM}_{0.1}$ vary greatly with the toxins they adsorb, adding complexity to public research. In many ways, the study of $\mathrm{PM}_{0.1}$ is at the frontier of air pollution research. As they are better understood, these particles should be more easily controlled. $\mathrm{PM}_{0.1}$, as with other air pollution, are avoidable and correctable health risks. Halting or reducing pollution should promptly result in improved health status ${ }^{78}$. Undoubtedly, more research is needed.

\section{Conflict of interest}

The author declares no conflict of interest.

\section{Publisher's note}

Springer Nature remains neutral with regard to jurisdictional claims in published maps and institutional affiliations.

Received: 26 December 2019 Accepted: 17 January 2020.

Published online: 17 March 2020

\section{References}

1. Schraufnagel, D. E. et al. Air pollution and noncommunicable diseases: a review by the Forum of International Respiratory Societies' Environmental Committee, Part 1: the damaging effects of air pollution. Chest 155, 409-416 (2019).
2. Schraufnagel, D. E. et al. Air pollution and noncommunicable diseases: a review by the Forum of International Respiratory Societies' Environmental Committee, Part 2: air pollution and organ systems. Chest 155, 417-426 (2019).

3. Li, N. et al. A work group report on ultrafine particles (American Academy of Allergy, Asthma \& Immunology): why ambient ultrafine and engineered nanoparticles should receive special attention for possible adverse health outcomes in human subjects. J. Allergy Clin. Immunol. 138, 386-396 (2016).

4. Morawska, L., Ristovski, Z., Jayaratne, R., Keogh, D. U. \& Ling, X. Ambient nano and ultrafine particles from motor vehicle emissions: characteristics, ambient processing and implications on human exposure. Atmos. Environ. 42, 8113-8138 (2008).

5. Wang, G. et al. Persistent sulfate formation from London Fog to Chinese haze. Proc. Natl Acad. Sci. USA 113, 13630-13635 (2016).

6. Karner, A. A., Eisinger, D. S. \& Niemeier, D. A. Near-roadway air quality: synthesizing the findings from real-world data. Environ. Sci. Technol. 44, 5334-5344 (2010).

7. Frank, B., Schuster, M. E., Schlogl, R. \& Su, D. S. Emission of highly activated soot particulate- the other side of the coin with modern diesel engines. Angew. Chem. Int. Ed. Engl. 52, 2673-2677 (2013).

8. Park, B. et al. Hazard and risk assessment of a nanoparticulate cerium oxidebased diesel fuel additive-a case study. Inhal. Toxicol. 20, 547-566 (2008).

9. Meng, $X$. et al. Size-fractionated particle number concentrations and daily mortality in a Chinese city. Environ. Health Perspect. 121, 1174-1178 (2013).

10. Frampton, M. W. Systemic and cardiovascular effects of airway injury and inflammation: ultrafine particle exposure in humans. Environ. Health Perspect. 109(Suppl. 4), 529-532 (2001).

11. Aalto, P. et al. Aerosol particle number concentration measurements in five European cities using TSI-3022 condensation particle counter over a threeyear period during health effects of air pollution on susceptible subpopulations. J. Air Waste Manag. Assoc. (1995) 55, 1064-1076 (2005).

12. de Jesus, A. L. et al. Ultrafine particles and PM2.5 in the air of cities around the world: are they representative of each other? Environ. Int. 129, 118-135 (2019).

13. Yacobi, N. R. et al. Mechanisms of alveolar epithelial translocation of a defined population of nanoparticles. Am. J. Respir. Cell Mol. Biol. 42, 604-614 (2010).

14. van Niel, G., D'Angelo, G. \& Raposo, G. Shedding light on the cell biology of extracellular vesicles. Nat. Rev. Mol. Cell Biol. 19, 213-228 (2018).

15. Moller, W. et al. Deposition, retention, and translocation of ultrafine particles from the central airways and lung periphery. Am. J. Respir. Crit. Care Med 177, 426-432 (2008).

16. Oberdorster, G., Ferin, J. \& Lehnert, B. E. Correlation between particle size, in vivo particle persistence, and lung injury. Environ. Health Perspect. 102(Suppl. 5), 173-179 (1994).

17. Shi, H., Magaye, R., Castranova, V. \& Zhao, J. Titanium dioxide nanoparticles: a review of current toxicological data. Part. Fibre Toxicol. 10, 15 (2013).

18. Weibel, E. W. The Pathway for Oxygen, Vol. 340 (Harvard University Press, 1984).

19. Weiber, E. W. Sterologic Methods: Practical Methods for Biological Morphometry (Academic Press, 1979).

20. Cassee, F. R. et al. Particle size-dependent total mass deposition in lungs determines inhalation toxicity of cadmium chloride aerosols in rats. Application of a multiple path dosimetry model. Arch. Toxicol. 76, 277-286 (2002).

21. Donaldson, K. et al. The pulmonary toxicology of ultrafine particles. J. Aerosol Med. 15, 213-220 (2002)

22. Oberdorster, G. Significance of particle parameters in the evaluation of exposure-dose-response relationships of inhaled particles. Inhal. Toxicol. 8 (Suppl.), 73-89 (1996).

23. Ibald-Mulli, A., Wichmann, H. E., Kreyling, W. \& Peters, A. Epidemiological evidence on health effects of ultrafine particles. J. Aerosol Med. 15, 189-201 (2002).

24. Viitanen, A. K., Uuksulainen, S., Koivisto, A. J., Hameri, K. \& Kauppinen, T. Workplace measurements of ultrafine particles-a literature review. Ann. Work Expo. Health 61, 749-758 (2017).

25. Oberdorster, G. et al. Principles for characterizing the potential human health effects from exposure to nanomaterials: elements of a screening strategy. Part. Fibre Toxicol. 2, 8 (2005).

26. Shvedova, A. A. et al. Unusual inflammatory and fibrogenic pulmonary responses to single-walled carbon nanotubes in mice. Am. J. Physiol. Lung Cell. Mol. Physiol. 289, L698-L708 (2005).

27. Powell, J. J. et al. Immune potentiation of ultrafine dietary particles in normal subjects and patients with inflammatory bowel disease. J. Autoimmun. 14, 99-105 (2000). 
28. Song, S. et al. Exposure to ambient ultrafine particles and urinary 8-hydroxyl-2deoxyguanosine in children with and without eczema. Sci. Total Environ. 458460, 408-413 (2013)

29. Lansdown, A. B. \& Taylor, A. Zinc and titanium oxides: promising UV-absorbers but what influence do they have on the intact skin? Int. J. Cosmet. Sci. 19, 167-172 (1997)

30. Chang, C., Demokritou, P., Shafer, M. \& Christiani, D. Physicochemical and toxicological characteristics of welding fume derived particles generated from real time welding processes. Environ. Sci. Process. Impacts 15, 214-224 (2013).

31. Oberdorster, G., Gelein, R. M., Ferin, J. \& Weiss, B. Association of particulate air pollution and acute mortality: involvement of ultrafine particles? Inhal. Toxicol. 7, 111-124 (1995)

32. Nordenhall, C. et al. Airway inflammation following exposure to diesel exhaust: a study of time kinetics using induced sputum. Eur. Respir. J. 15, 1046-1051 (2000).

33. Osunsanya, T., Prescott, G. \& Seaton, A. Acute respiratory effects of particles: mass or number? Occup. Environ. Med. 58, 154-159 (2001).

34. Yang, J., Kim, Y. K., Kang, T. S., Jee, Y. K. \& Kim, Y. Y. Importance of indoor dust biological ultrafine particles in the pathogenesis of chronic inflammatory lung diseases. Environ. Health Toxicol. 32, e2017021 (2017).

35. Peters, A., Wichmann, H. E., Tuch, T., Heinrich, J. \& Heyder, J. Respiratory effects are associated with the number of ultrafine particles. Am. J. Respir. Crit. Care Med. 155, 1376-1383 (1997)

36. von Klot, S. et al. Increased asthma medication use in association with ambient fine and ultrafine particles. Eur. Respir. J. 20, 691-702 (2002).

37. Andersen, Z. J. et al. Size distribution and total number concentration of ultrafine and accumulation mode particles and hospital admissions in children and the elderly in Copenhagen, Denmark. Occup. Environ. Med. 65, 458-466 (2008).

38. Diaz-Robles, L. A. et al. Health risks caused by short term exposure to ultrafine particles generated by residential wood combustion: a case study of Temuco, Chile. Environ. Int. 66, 174-181 (2014).

39. Weichenthal, S. et al. Long-term exposure to ambient ultrafine particles and respiratory disease incidence in in Toronto, Canada: a cohort study. Environ. Health 16, 64 (2017).

40. Clifford, S. et al. Effects of exposure to ambient ultrafine particles on respiratory health and systemic inflammation in children. Environ. Int. 114, 167-180 (2018).

41. Duffin, R., Mills, N. L. \& Donaldson, K. Nanoparticles-a thoracic toxicology perspective. Yonsei Med. J. 48, 561-572 (2007)

42. Hildebrandt, K. et al. Short-term effects of air pollution: a panel study of blood markers in patients with chronic pulmonary disease. Part. Fibre Toxicol. 6, 25 (2009).

43. Olsen, Y. et al. Vascular and lung function related to ultrafine and fine particles exposure assessed by personal and indoor monitoring: a cross-sectional study. Environ. Health 13, 112 (2014).

44. Samet, J. M. et al. Concentrated ambient ultrafine particle exposure induces cardiac changes in young healthy volunteers. Am. J. Respir. Crit. Care Med 179, 1034-1042 (2009).

45. Devlin, R. B. et al. Controlled exposure of humans with metabolic syndrome to concentrated ultrafine ambient particulate matter causes cardiovascular effects. Toxicol. Sci. 140, 61-72 (2014).

46. Downward, G. S. et al. Long-term exposure to ultrafine particles and incidence of cardiovascular and cerebrovascular disease in a prospective study of a Dutch Cohort. Environ. Health Perspect. 126, 127007 (2018).

47. Bai, L. et al. Associations of long-term exposure to ultrafine particles and nitrogen dioxide with increased incidence of congestive heart failure and acute myocardial infarction. Am. J. Epidemiol. 188, 151-159 (2019).

48. Li, Y. et al. Association of long-term near-highway exposure to ultrafine particles with cardiovascular diseases, diabetes and hypertension. Int. J. Environ. Res. Public Health 14, https://doi.org/10.3390/ijerph14050461 (2017).

49. Andersen, Z. J. et al. Association between short-term exposure to ultrafine particles and hospital admissions for stroke in Copenhagen, Denmark. Eur. Heart J. 31, 2034-2040 (2010).

50. Pieters, N. et al. Blood pressure and same-day exposure to air pollution at school: associations with nano-sized to coarse PM in children. Environ. Health Perspect. 123, 737-742 (2015).

51. Stolzel, M. et al. Daily mortality and particulate matter in different size classes in Erfurt, Germany. J. Expo. Sci. Environ. Epidemiol. 17, 458-467 (2007).

52. Liu, L. et al. Size-fractioned particulate air pollution and cardiovascular emergency room visits in Beijing, China. Environ. Res. 121, 52-63 (2013).

53. Ostro, B. et al. Associations of mortality with long-term exposures to fine and ultrafine particles, species and sources: results from the California Teachers Study Cohort. Environ. Health Perspect. 123, 549-556 (2015).
54. Pekkanen, J. et al. Particulate air pollution and risk of ST-segment depression during repeated submaximal exercise tests among subjects with coronary heart disease: the Exposure and Risk Assessment for Fine and Ultrafine Particles in Ambient Air (ULTRA) study. Circulation 106, 933-938 (2002).

55. Moller, K. L. et al. Cardiovascular disease and long-term occupational exposure to ultrafine particles: a cohort study of airport workers. Int. J. Hyg. Environ. Health 223, 214-219 (2020).

56. Oberdorster, G. et al. Translocation of inhaled ultrafine particles to the brain. Inhal. Toxicol. 16, 437-445 (2004).

57. Tian, L. et al. Correlation of regional deposition dosage for inhaled nanoparticles in human and rat olfactory. Part. Fibre Toxicol. 16, 6 (2019).

58. Heusser, K. et al. Ultrafine particles and ozone perturb norepinephrine clearance rather than centrally generated sympathetic activity in humans. Sci. Rep. 9, 3641 (2019).

59. Allen, J. L. et al. Developmental exposure to concentrated ambient ultrafine particulate matter air pollution in mice results in persistent and sexdependent behavioral neurotoxicity and glial activation. Toxicol. Sci. $\mathbf{1 4 0}$ 160-178 (2014)

60. Onoda, A., Takeda, K. \& Umezawa, M. Dose-dependent induction of astrocyte activation and reactive astrogliosis in mouse brain following maternal exposure to carbon black nanoparticle. Part. Fibre Toxicol. 14, 4 (2017).

61. Kumar, S., Verma, M. K. \& Srivastava, A. K. Ultrafine particles in urban ambient air and their health perspectives. Rev. Environ. Health 28, 117-128 (2013).

62. Bos, I. et al. No exercise-induced increase in serum BDNF after cycling near a major traffic road. Neurosci. Lett. 500, 129-132 (2011).

63. Laurent, $\mathrm{O}$. et al. Sources and contents of air pollution affecting term low birth weight in Los Angeles County, California, 2001-2008. Environ. Res. 134, 488-495 (2014).

64. Nyarku, M. et al. Schoolchildren's personal exposure to ultrafine particles in and near Accra, Ghana. Environ. Int. 133, 105223 (2019).

65. Mazaheri, M. et al. Characteristics of school children's personal exposure to ultrafine particles in Heshan, Pearl River Delta, China-a pilot study. Environ. Int. 132, 105134 (2019).

66. Lee, E. S., Fung, C. C. \& Zhu, Y. Evaluation of a high efficiency cabin air (HECA) filtration system for reducing particulate pollutants inside school buses. Environ. Sci. Technol. 49, 3358-3365 (2015).

67. Londahl, J. et al. Experimental determination of the respiratory tract deposition of diesel combustion particles in patients with chronic obstructive pulmonary disease. Part. Fibre Toxicol. 9, 30 (2012).

68. Glantz, S. A. \& Bareham, D. W. E-cigarettes: use, effects on smoking, risks, and policy implications. Annu. Rev. Public Health 39, 215-235 (2018).

69. Lechasseur, A. et al. Variations in coil temperature/power and e-liquid constituents change size and lung deposition of particles emitted by an electronic cigarette. Physiol. Rep. 7, e14093 (2019).

70. Bai, L. et al. Exposure to ambient ultrafine particles and nitrogen dioxide and incident hypertension and diabetes. Epidemiology 29, 323-332 (2018).

71. Vora, R. et al. Inhalation of ultrafine carbon particles alters heart rate and heart rate variability in people with type 2 diabetes. Part. Fibre Toxicol. 11, 31 (2014).

72. Peters, A. et al. Elevated particle number concentrations induce immediate changes in heart rate variability: a panel study in individuals with impaired glucose metabolism or diabetes. Part. Fibre Toxicol. 12, 7 (2015).

73. Sun, Y. et al. Size-fractioned ultrafine particles and black carbon associated with autonomic dysfunction in subjects with diabetes or impaired glucose tolerance in Shanghai, China. Part. Fibre Toxicol. 12, 8 (2015).

74. Pagano, P., De Zaiacomo, T., Scarcella, E., Bruni, S. \& Calamosca, M. Mutagenic activity of total and particle-sized fractions of urban particulate matter. Environ. Sci. Technol. 30, 3512-3516 (1996).

75. Kawanaka, Y., Matsumoto, E., Sakamoto, K. \& Yun, S. J. Estimation of the contribution of ultrafine particles to lung deposition of particle-bound mutagens in the atmosphere. Sci. Total Environ. 409, 1033-1038 (2011).

76. Stanton, M. F. et al. Relation of particle dimension to carcinogenicity in amphibole asbestoses and other fibrous minerals. J. Natl. Cancer Inst. 67, 965-975 (1981)

77. World Health Organization. Infographic: Air Pollution - the Silent Killer http:// www.euro.who.int/en/health-topics/environment-and-health/air-quality/ news/news/2018/5/over-half-a-million-premature-deaths-annually-in-theeuropean-region-attributable-to-household-and-ambient-air-pollution/ infographic-air-pollution-the-silent-killer (2019).

78. Schraufnagel, D. E. et al. Health benefits of air pollution reduction. Ann. Am. Thorac. Soc. 16, 1478-1487 (2019). 